\title{
Does Intensive Soccer Playing During the Growth Period Lead to Leg Length Discrepancies?
}

\section{(ㄷ) (i) (우)}

\author{
Authors \\ Jean-Luc Guer ${ }^{1,2}$, Sylvain Blanchard¹, Marta Catalina Harnagea², Eric Lopez², Michel Behr
}

\author{
Affiliations \\ 1 Laboratoire de Biomécanique Appliquée, Aix-Marseille \\ Univ, IFSTTAR, LBA UMR_T24, Marseille, France \\ 2 Wizwedge SARL, Research Department, Marseille, France
}

\section{Key word}

limb length discrepancy, soccer, growth plate, lower

extremity

received 20.02.2017

revised 23.06.2017

accepted $\quad 05.07 .2017$

\author{
Bibliography \\ DOI https://doi.org/10.1055/s-0043-117600 \\ Sports Medicine International Open 2017; 1: E183-E187 \\ (c) Georg Thieme Verlag KG Stuttgart · New York \\ ISSN 2367-1890 \\ Correspondence \\ Dr. Michel BEHR, PhD \\ Laboratoire de Biomécanique Appliquée \\ Aix-Marseille Univ, IFSTTAR, LBA UMR_T24 \\ Boulevard Dramard \\ F-13916, Marseille \\ France \\ Tel.: + 33/49/1658 014, Fax: + 33/49/1658 019 \\ michel.behr@ifsttar.fr
}

\begin{abstract}
Leg length discrepancies (LLD) are a common reason for podiatry consultations and can affect up to $90 \%$ of the overall population. Furthermore, it is widely recognized that intensive participation in certain sports can alter bone development. The aim of this study is to explore any possible relation between playing soccer and the appearance or evolution of LLD, by means of a retrospective study based on the analysis of case reports of patients followed for foot or plantar troubles. Case reports were selected in the archives of a podiatric clinic for the period between 2002 and 2016 among patients who declared regular to intensive soccer playing, aged 13 years or more. LLD was detected in the vast majority of cases (95 cases out of 104). Pearson correlation coefficients were computed and revealed a strong correlation between the laterality of the kicking limb and that of the shorter leg. The shorter limb was on the side of the kicking leg in $96 \%$ of the cases when considering the players who began practice before the age of 13 , and only $53 \%$ of the cases for others. Intensive soccer playing at a young age may encourage the appearance and evolution of a real LLD.
\end{abstract}

\section{Introduction}

Real leg-length discrepancy (LLD), or anisomelia, is defined as the situation in which the lower limbs are of significantly different lengths. LLD is a common problem that may affect up to $90 \%$ of the population $[9,18,22,25,26]$. It may be of structural origin, i. e., related to a difference in bone length in the lower limb, of congenital origin, or the result of an operation [25]. The amplitude is lower than $10 \mathrm{~mm}$ for $80 \%$ of the population, and between 10 and $15 \mathrm{~mm}$ for $15 \%$ of the population [9]. It has also been reported that LLDs exceeding $20 \mathrm{~mm}$ affect at least one person out of 1,000 [19].

According to Knutson et al. [9], the right leg is statistically more often the shorter limb (in $53 \%$ to $75 \%$ of all cases, depending on the study) when looking at a heterogeneous population balanced between men and women. LLD is apparently not gender-specific [21], and its amplitude does not appear to differ statistically between one side and the other, according to the aforementioned study.

Clinical incidences of LLDs are multiple. LLD is known to favor pain along the spinal column, starting with lumbar pain [1,5]. LLDs also contribute to pain in the sacroiliac joint $[4,6,15]$, as well as coxalgia and gonalgia, which are the result of a functional overload that is usually located in the longer leg when standing $[17,24]$ and in the shorter leg when walking or running. These troubles can evolve toward osteoarthritis over the longer term [6]. The foot on 
the longer leg may have a tendency toward pronation [14] and greater eversion [27]. The foot on the shorter leg may have a tendency toward supination [20].

Furthermore, it is widely expected that intensive sports activities, notably by young people in the growth period, is a risk factor for developing or aggravating LLD [8], probably due to repeated impacts that disturb the development and growth of epiphyseal cartilage [13]. LLD is also favorable to stress fractures in certain categories of high-level athletes [2,12]. Lastly, soccer appears to be a sport in which young players are not spared. In fact, intensive playing, especially during the period of skeletal immaturity, is known to lead to cam deformity, often accompanied by a $\operatorname{LLD}[3,7,16,23]$. It should be pointed out, however, that high-level soccer playing (and the intensity thereof) is not the only factor that encourages the development of cam deformity in young adults $[7,16]$. An increase in bone mineral content in the lower limbs of prepubescent boys can also occur, to the detriment of the non-weight-bearing bones [28].

In this context, the assumption was made that playing soccer during the prepubescent growth period could be a triggering or aggravating factor for LLDs. This paper deals with a retrospective study of podiatric records on two groups of regular to intensive soccer players: those who began their practice before or during their growth period, and those who began after their growth period.

\section{Methods}

Our approach was based on a retrospective study of the archives of case reports for patients who had consulted the same podiatric clinic in Marseille, France, between 2002 and 2016, and meets the SMIO's ethical standards [10]. This clinic welcomes a varied population of all ages, whether involved in sports or not, although we are unable a priori to consider them as representative of any particular category of people. Each patient admitted into the clinic underwent a systematic clinical examination always performed by the same experienced podiatrist, including:

- A questionnaire, used first of all to gather information on patients' height, weight, sex, and reason for consulting. Any event in a patient's medical history and possible co-morbidities were also recorded (traumas, surgeries), as well as laterality (right-footed, left-footed, bilateral or contralateral). Information concerning work status and any sports activities were gathered: sport or sports played, level and intensity of play. If the patient declared any period of practice stoppage (due to medical recovery, for example), the cumulative duration of stoppage was also recorded. For soccer players, kicking-leg laterality was also recorded;

- An unloaded leg examination was performed with the patient lying on the examination table. First, a lower-limb joint mobility test was performed on the ankle, knee and hip to identify any joint dysfunction (loss of mobility and/or functional pain when mobilized). All information was recorded in the patient's medical history file. The position of the table was then raised slightly to raise the patient's back. With the pelvis aligned against the back of the table, LLD was assessed by measuring the distance between the medial malleoli of the tibias, according to the procedure known as the tape meas- urement method (TMM) in the literature. TMM reliability and validity was recently compared to the $\mathrm{CT}$ scanogram method and showed high interobserver reliability, with an ICC of 0.924 , and good accuracy, with an ICC of 0.805 [11].

Note that LLD amplitude was also confirmed by reading recent $X$-ray images (standing, front view of the pelvis) taken prior to consultation and already in each patient's possession. This value was also recorded in the patient's medical history file.

- A loaded leg examination was performed using an electronic podobaroscope (Capron Eclipse 3000, France) to assess the load balance between the lower limbs, identify the position of the center of gravity in static posture and measure pressure distributions. The pressure distributions image was added to the patient's file. The procedure was then completed with a podoscopic examination carried out to analyze the plantar contact surfaces and to detect any pronation/supination of the foot.

- A qualitative walking dynamics examination was performed by observing the patient walking along a $10 \mathrm{~m}$ hallway, first with shoes and then barefoot, to assess compensatory pronation/supination while walking. Lastly, shoes were examined to record the kind of shoes worn by the patient and the level of damage.

Each case in the clinic patient's database was reviewed by a group of health professionals including a podiatrist, an MD specialized in sports medicine and two PhDs in biomechanics. The cases that met the following inclusion criteria were selected by this group of experts:

- Files mentioning "soccer player" with a playing level greater than 3 ( 3 = regular player, 4 = registered soccer club member, $5=$ professional player);

- Patient's age was greater than or equal to 13;

- Patient's file was exhaustive. The files were considered exhaustive if they at least included data concerning the patient's height, weight and age at the time of the consultation, the patient's history of trauma or surgery on the limbs, limb laterality, LLD laterality, its amplitude measured during the unloaded leg examination (discussed above) and, lastly, kicking-leg laterality.

Patient's files indicating possible co-morbidities were systematically excluded from the study.

Two subgroups were then defined as follows: SubGroup M1 would include players who began playing soccer before the age of 13 , i. e., before or during their growth period, and SubGroup M2 would include players who began their practice after the age of 13. Female patients' files were gathered into SubGroup F.

The statistical analysis first dealt with a descriptive analysis of the population and the average LLD characteristics recorded in our population in terms of laterality (right or left) and intensity (low to severe).

Pearson's correlation tests, computed as the covariance of two variables divided by the product of their standard deviations, were then performed using Statistica software (Livermore, MA) to look for possible correlations. The first variable was the recorded amplitude of the LLD. The second variable was alternatively:

the age subgroup of the male patients (M1 or M2), the intensity of soccer play ( 3 = regular player, 4 = registered soccer club mem- 


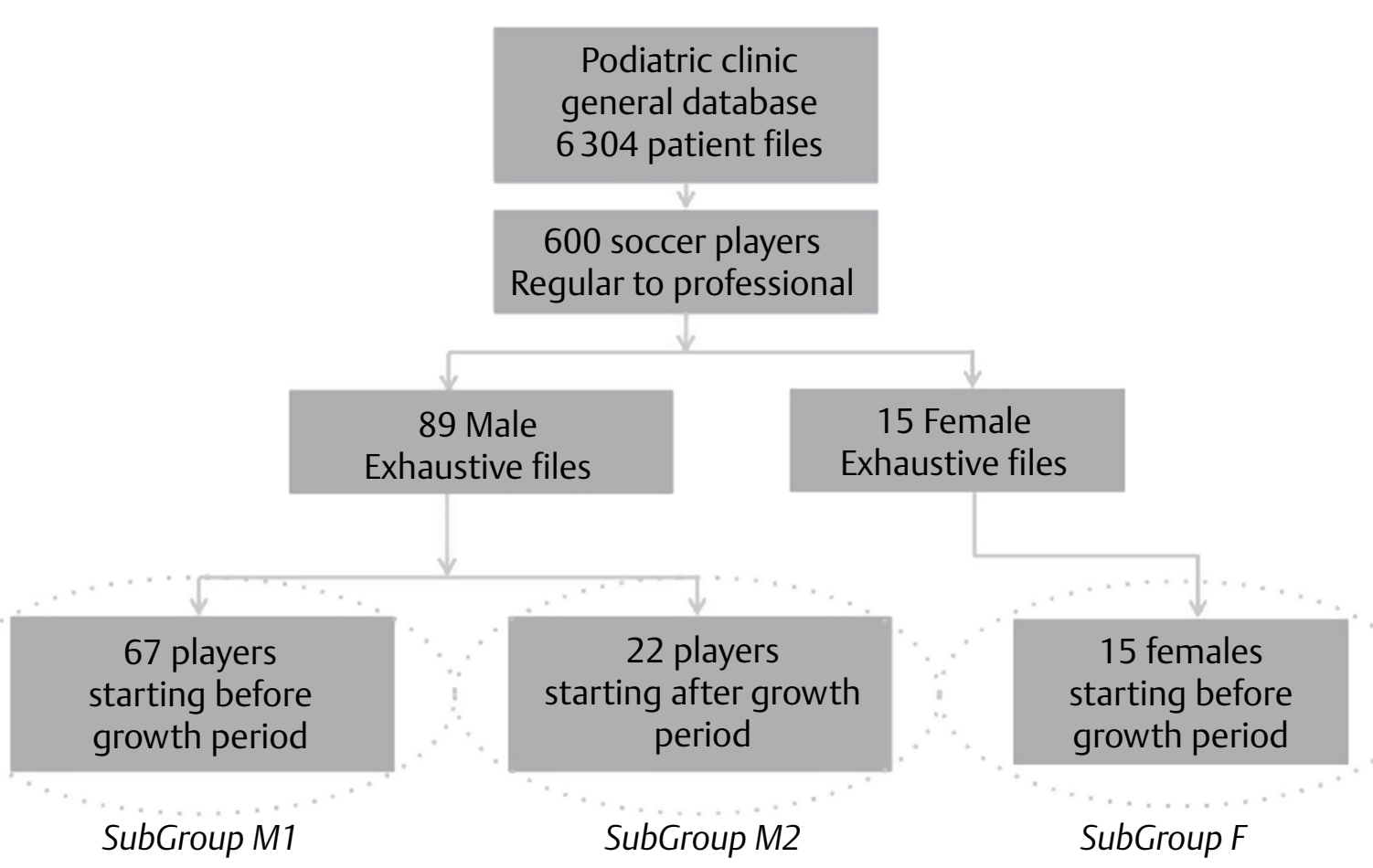

- Fig. 1 Database organization and subgroups.

ber, 5 = professional player), the cumulative duration of stoppage of play.

Factors were considered as correlated if the correlation coefficient $R$ had an absolute value greater than 0.5 . Possible confounding effects such as age and gender were considered across the three above-defined subgroups.

\section{Results}

Out of all the case files of patients who consulted the podiatry clinic during the 2002-2016 period, a total of 600 patients stated that they played soccer regularly (197), as registered soccer club members (330), or as professional players (73). Selected files and subgroups are illustrated in $>$ Fig. 1. Among these case files, a total of 15 complete files for female players and 89 complete files for male players over the age of 13 and who declared being regular to professional players were ultimately selected for this study. All female players declared that they had begun playing soccer before or during the growth period. Among the male population, 67 patients declared that they had begun playing soccer before or during the growth period and 22 thereafter. The general characteristics of our population and the averages for the groups studied are summarized in $>$ Table 1.

LLD was detected in 95 cases out of the 104 case files selected. Data concerning the LLDs detected in our population are summarized in > Table 2. The average amplitude of the LLD detected clinically (vertical distance between the two medial malleoli) was $7.9 \mathrm{~mm}$ in our total population. It was $6.5 \mathrm{~mm}$ for women (Subgroup F) and $8.1 \mathrm{~mm}$ for men. It was $8.3 \mathrm{~mm}$ for men who had
- Table 1 General characteristics of the population.

\begin{tabular}{|l|c|c|c|}
\hline & Women & Men & Total Pop. \\
\hline Number & 15 & 89 & 104 \\
\hline Weight $(\mathrm{kg})$ & $65.1(28.9)$ & $72.7(15.8)$ & $71.5(18.0)$ \\
\hline Height $(\mathrm{cm})$ & $157.5(29.6)$ & $174.3(14.7)$ & $171.0(18.3)$ \\
\hline Age & $21.3(6.5)$ & $28.2(10.04)$ & $27.1(10.1)$ \\
\hline
\end{tabular}

begun playing soccer before or during the growth period and $6.8 \mathrm{~mm}$ for the others. The maximum clinically recorded value for all the files was $17.0 \mathrm{~mm}$.

In all the files considered, the shorter limb was on the kickingleg side in $87.5 \%$ of the cases. This proportion reached over $96 \%$ of all cases in age SubGroup M1, whereas it was only observed in $53 \%$ of the cases in age SubGroup M2.

The results of the analysis of correlation among LLD characteristics are summed up in $>$ Table 3.

\section{Discussion}

Based on our current understanding, it can be assumed that excess stress on the skeleton, notably during the growth period, may have a significant effect on bone development mechanisms and could therefore be involved in the appearance and/or development of real LLDs. Moreover, our clinical observations and personal experience have led us to believe that playing soccer, in other words, certain forms of bone stress seen in this sport, could have a specific effect on dissymmetrical leg growth. In investigating this question, and because, as far as we know, it has not been examined in any 
Table 2 Characteristics of LLDs detected in the population.

\begin{tabular}{|c|c|c|c|c|c|}
\hline & Total Pop. & Women & Men & Men $<13$ & Men $>13$ \\
\hline Right LLD (\%) & 68 & 67 & 69 & 72 & 59 \\
\hline Left LLD (\%) & 32 & 33 & 31 & 28 & 41 \\
\hline LLD < $5 \mathrm{~mm}(\%)$ & 30 & 67 & 24 & 25 & 18 \\
\hline LLD 5-10 mm (\%) & 65 & 6 & 71 & 85 & 27 \\
\hline LLD> $10 \mathrm{~mm}(\%)$ & 5 & 27 & 6 & 7 & 0 \\
\hline
\end{tabular}

- Table 3 LLD correlations ( $\mathrm{R}$ = Pearson's correlation coefficient).

\begin{tabular}{|l|l|l|c|}
\hline Factor $\mathbf{1}$ & Factor $\mathbf{2}$ & Factor $\mathbf{3}$ & $\mathbf{R}$ \\
\hline $\begin{array}{l}\text { Presence of } \\
\text { LLD }\end{array}$ & Playing soccer & 1.0 \\
\hline $\begin{array}{l}\text { Laterality of } \\
\text { the LLD }\end{array}$ & Laterality of the LLs & 0.73 \\
\hline $\begin{array}{l}\text { Laterality of } \\
\text { the LLD }\end{array}$ & Laterality of the LLs & Men<13 & 0.92 \\
\hline $\begin{array}{l}\text { Laterality of } \\
\text { the LLD }\end{array}$ & Laterality of the LLs & Men>13 & -0.06 \\
\hline $\begin{array}{l}\text { Amplitude } \\
\text { of the LLD }\end{array}$ & Age at which play began & -0.16 \\
\hline $\begin{array}{l}\text { Amplitude } \\
\text { of the LLD }\end{array}$ & Intensity of play & 0.10 \\
\hline $\begin{array}{l}\text { Amplitude } \\
\text { of the LLD }\end{array}$ & $\begin{array}{l}\text { Duration of cumulative } \\
\text { stoppage of playing }\end{array}$ & -0.01 \\
\hline
\end{tabular}

other study, we analyzed the clinical files of 104 patients who consulted a clinic between 2002 and 2016, all of whom, whether men or women, were soccer players and played their sport regularly to professionally.

Our results show that, in a population made up of male and female soccer players engaging in regular or intensive play, real LLD is found almost systematically, even though it may be considered small ( $<5 \mathrm{~mm}$ ) in the vast majority of cases. These results are consistent with literature $[9,18,22,25,26]$. We also observed that the shorter lower limb is often the kicking leg, especially and quite markedly, when the patient in question started playing soccer before or during the growth period (Subgroup 1). The correspondence between laterality and the shorter lower limb was expected because the tendency had already been observed elsewhere [9], but here it appears to be very significant, probably due to the specific population being studied, i. e., regular to professional soccer players, and most of all soccer players who already experienced plantar troubles.

However, no obvious correlation between the amplitude of the LLD and the intensity of soccer playing, the age subgroup or the cumulative duration of stoppage could be observed.

Our observations suggest that there may be a link between playing soccer, notably during the growth period, and slowed bone growth in the left leg in a left-legged patient, and in the right leg in a right-legged patient. As previously reported [28], in a heterogeneous population right-legged people tend to have a shorter right leg and left-legged people a shorter left leg, but the tendency becomes even more obvious and very significant on the scale of the population studied here. We have already discussed the assumption that the main particularity of a soccer player in terms of stress induced in the lateralized lower limb concerns the maneuver of kicking the ball. The long-term, repeated action of kicking a ball may be what significantly alters bone growth and leads to an LLD in which the shorter leg is the lateralized limb. This assumption is reinforced by several observations:

- First of all, the significant effect of repeated impacts on bone growth is well known, because these impacts can disturb and slow down the development of epiphyseal cartilage [13], or because they significantly modify the bone mineralization process $[3,7,16,23]$.

- Secondly, on the scale of our population, cases in which the lower limb is shorter on the side opposite the kicking limb mostly concern patients who stated that they had begun playing soccer regularly after the age of 13 , i. e., at the end of or after their prepubescent growth period.

- Some particular cases in our database do illustrate the tendency that we observed, although they are not sufficient to draw any conclusions as to a causal link. We can point to the case of a patient who came in for the first time at the age of 6 with a real LLD of $6 \mathrm{~mm}$ on the side opposite to the kicking leg. The patient continued to come to the clinic for 4 years, during which he played soccer in a club. During that period, we first observed an attenuation in his LLD, then a progressive inversion of his LLD toward the kicking leg. After 4 years, his LLD was calculated at $6 \mathrm{~mm}$ on the kicking-leg side.

Nowadays, according to the FIFA recommendations, the weight of a soccer ball should be between 310 and $370 \mathrm{~g}$ for children between 6 and 11 years of age, and between 400 and $450 \mathrm{~g}$ for players older than that, with no distinction between age groups. If the relationship that we observed between LLD and laterality proves to be true, a more precise assessment of the link between ball weight and the risk of growth disturbances in children should be undertaken, in our opinion, to ensure better adaptation of ball weight to the age of young players. An initial approach could be to quantify the impact energy when kicking a ball as a function of the weight of the ball, the size of the player and the dynamics of the gesture, each of these variables being specific to the age of the player. At the same time, reflections on optimal physical preparation should be carried out, taking into account the risk of altering bone growth and the amount of play to make adaptations for the age of the player.

The external validity of our study has several limitations. First of all, all the case files were compiled by one single, although experienced, podiatrist. The data recorded in the files should therefore be considered as operator-dependent. In order to limit this possible effect, we looked only at the period (2002 to 2016), when the practitioner had already acquired solid experience in clinical examinations and his protocol could be considered well-established and systematic. Then, because the entire study was carried out at a sin- 
gle clinic, there is a risk of making observations on a particular population that is not representative of the general population. Here again, a rapid analysis of the patients' addresses and of their professions shows that the patients did not come from a very narrow neighborhood but, on the contrary, had a varied geographical origin, mostly in the city of Marseille, although a significant percentage also came from outside the city. Lastly, the database studied here concerns patients, in other words people who made the effort to go to a podiatrist and who therefore a priori had a trouble with their plantar surface contact or related problems. Under these conditions, our results cannot be transposed directly to the general population: our observations are representative only of intensive soccer players who clinically suffer from podiatric issues.

\section{Conclusion}

Playing soccer intensively before or during the growth period may encourage the appearance and development of a real leg-length discrepancy (LLD). More precisely, our observations indicate that growth is slowed in the lower limb used to kick the ball, among other tasks, and may lead to an LLD, which did not exceed $17 \mathrm{~mm}$ in the cases we analyzed. The weight of the ball and an overly intensive play regimen may be aggravating factors.

\section{Acknowledgements}

This study received no specific financial support.

\section{Conflict of Interest}

The authors declare that they have no conflict of interest.

\section{References}

[1] Agricola R, Bessems JH, Ginai AZ, Heijboer MP, van der Heijden RA, Verhaar JA, Weinans $\mathrm{H}$, Waarsing JH. The development of Cam-type deformity in adolescent and young male soccer players. Am J Sports Med 2012; 40: 1099-1106

[2] Amankwah K, Triolo R, Kirsch R, Audu M. A model-based study of passive joint properties on muscle effort during static stance. J Biomech 2006; 39: 2253-2263

[3] Bennell KL, Malcolm SA, Thomas SA, Reid SJ, Brukner PD, Ebeling PR, Wark JD. Risk factors for stress fractures in track and field athletes. A twelve-month prospective study. Am J Sports Med 1996; 24: 810-818

[4] Bopp HM. Peroarthrosis coxae oder Trochanterschmerz bei Beinlängedifferenzen? Orthop Praxis 1971; 10: 261-263

[5] Blake RL, Ferguson HJ. Correlation between limb length discrepancy and asymmetrical rearfoot position. J Am Podiatr Med Assoc 1993; 83: 625-633

[6] Buess-Watson E, Exner GU, Illi OE. Fractures about the knee: growth disturbances and problems of stability at long-term follow-up. Eur ] Pediatr Surg 1994; 4: 218-224
[7] Friberg O. Clinical symptoms and biomechanics of lumbar spine and hip joint in leg length inequality. Spine (Phila Pa 1976) 1983; 8: 643-651.

[8] Guichet JM, Spivak JM, Trouilloud P, Grammont PM. Lower limb-length discrepancy. An epidemiologic study. Clin Orthop Relat Res 1991; 272: 235-241

[9] Giles LG, Taylor JR. Low-back pain associated with leg length inequality. Spine 1981; 6: 510-521

[10] Harriss DJ, Atkinson G. Ethical standards in sports and exercise science research: 2016 update. Int J Sports Med 2015; 36: 1121-1124

[11] Jamaluddin S, Sulaiman AR, Imran MK, Juhara H, Ezane MA, Nordin S. Reliability and accuracy of the tape measurement method with a nearest reading of $5 \mathrm{~mm}$ in the assessment of leg length discrepancy. Singapore Med J 2011; 52: 681-684

[12] Johnson AC, Shaman MA, Ryan TG. Femoroacetabular impingement in former high-level youth soccer players. Am J Sports Med 2012; 40: 1342-1346

[13] Kaufman KR, Miller LS, Sutherland DH. Gait asymmetry in patients with limb-length inequality. J Pediatr Orthop 1996; 16: 144-150

[14] Kiapour A, Abdelgawad AA, Goel VK, Souccar A, Terai T, Ebraheim NA. Relationship between limb length discrepancy and load distribution across the sacroiliac joint-a finite element study. J Orthop Res 2012; 30: $1577-1580$

[15] Knutson GA. Anatomic and functional leg-length inequality: a review and recommendation for clinical decision-making. Part II. The functional or unloaded leg-length asymmetry. Chiropr Osteopat 2005; 20: 13-22

[16] Langer S. Structural leg shortage. A case report. J Am Podiatry Assoc 1976; 66: 38-40

[17] McCaw ST, Bates BT. Biomechanical implications of mild leg length inequality. Br J Sports Med 1991; 25: 10-13

[18] Maffulli N, Longo UG, Spiezia F, Denaro V. Sports injuries in young athletes: Long-term outcome and prevention strategies. Phys Sportsmed 2010; 38: 29-34

[19] Maffulli N, Longo UG, Spiezia F, Denaro V. Aetiology and prevention of injuries in elite young athletes. Med Sport Sci 2011; 56: 187-200

[20] Mahar RK, Kirby RL, MacLeod DA. Simulated leg-length discrepancy: Its effect on mean center-of-pressure position and postural sway. Arch Phys Med Rehabil 1985; 66: 822-824

[21] Murray KJ, Azari MF. Leg length discrepancy and osteoarthritis in the knee, hip and lumbar spine. J Can Chiropr Assoc 2015; 59: 226-237

[22] Raczkowski JW, Daniszewska B, Zolynski K. Functional scoliosis caused by leg length discrepancy. Arch Med Sci 2010; 6: 393-398

[23] Subotnick SI. Limb length discrepancies of the lower extremity (the short leg syndrome). J Orthop Sports Phys Ther 1981; 3: 11-16

[24] Swaminathan V, Cartwright-Terry M, Moorehead JD, Bowey A, Scott S]. The effect of leg length discrepancy upon load distribution in the static phase (standing). Gait Posture 2014; 40: 561-563

[25] Walsh M, Connolly P, Jenkinson A, O'Brien T. Leg length discrepancyan experimental study of compensatory changes in three dimensions using gait analysis. Gait Posture 2000; 12: 156-161

[26] Woerman AL, Binder-Macleod SA. Leg length discrepancy assessment: Accuracy and precision in five clinical methods of evaluation * J Orthop Sports Phys Ther 1984; 5: 230-239

[27] Yde J, Nielsen AB. Sports injuries in adolescents' ball games: Soccer, handball and basketball. Br J Sports Med 1990; 24: 51-54 